\title{
Interdisciplinary and experiential learning in urban development management education
}

\author{
Yawei Chen $^{1}$ (D) . Tom A. Daamen ${ }^{1} \cdot$ Erwin W. T. M. Heurkens $^{1} \cdot$ Wouter J. Verheul $^{1}$
}

Accepted: 19 July 2019 / Published online: 31 July 2019

(c) The Author(s) 2019

\begin{abstract}
To understand and deal with real urban development problems, urban planners, designers, and managers need to combine and synthesize a variety of academic and professional knowledge. As our urban challenges grow more complex, learning how to do this effectively becomes ever more important. For educators, this means teaching students how to work in interdisciplinary settings, i.e. how to jointly discover the different disciplinary dimensions of an urban problem, and how to reflectively design courses of action. In this paper, we explore and evaluate the components of such interdisciplinary experiential learning, develop a framework to design and analyse this type of courses, and use it to position and evaluate a specific urban development management course. Results show that, by performing and reflecting upon specific professional roles, the course stimulates students to both integrate different disciplines and reflect on an array of academic and practical insights. Based on our evaluation, we discuss several didactical aspects that may help lecturers to improve their interdisciplinary teaching in urban planning, design, and management courses-particularly when creating learning experiences in an increasingly diverse professional, societal and educational setting.
\end{abstract}

Keywords Interdisciplinary learning · Urban development management · Urban (re) development game $\cdot$ Role simulation $\cdot$ Theory and practice

Yawei Chen

Y.Chen@tudelft.nl

Tom A. Daamen

T.A.Daamen@tudelft.nl

Erwin W. T. M. Heurkens

E.W.T.M.Heurkens@tudelft.nl

Wouter J. Verheul

W.J.Verheul@tudelft.nl

1 Faculty of Architecture and the Built Environment, Department of Management in the Built Environment, Delft University of Technology, Delft, The Netherlands 


\section{Introduction}

'Universities tend to see tasks or problems through the lens of their subjects and courses. When an issue cuts across the provinces of departments or professions, it requires "interdisciplinary" treatment. But because academic provinces are also political territories, interdisciplinary projects are quickly politicized ...' (Schön 1987: 310)

The current pace of urbanization in the world resonates strongly with an increased awareness of common urban challenges. Finding ways to grow our increasingly regional economies sustainably, making cities resilient to the effects of climate change, and preparing our built environment for a scarcity of crucial resources-like water, food, and energy - are all high on urban agendas worldwide. Politicians, planners, engineers, architects and other professionals who shape the (re)development of cities and urban regions are facing tremendous threats, but also opportunities.

The challenge that practitioners often encounter in managing or governing urban development processes is complexity. An urban development manager-who may have a design, planning, real estate, or other disciplinary background-needs to assess and cohere the knowledge and skills that different disciplines have to offer, as urban development processes span across several industry sectors and policy domains, and are concerned with processes on multiple institutional levels and spatial scales. Therefore, education in what we term urban development management (UDM) should help students become familiar with a variety of built environment-related disciplines, such as architecture, urbanism, real estate development and finance, but also with urban economics, geography and sociology. Students can obviously not be trained with equal depth in every discipline, but being able to explore and define the different dimensions of urban problems and potential solutions does require a certain level of knowledge and skills. Moreover, students should gain the competence to relate and integrate different disciplinary perspectives, i.e. to work and think with an interdisciplinary approach.

Within and beyond university, it may be of growing concern that many of the problems faced in cities today do not follow the disciplinary boundaries of our academies or professions. Indeed, it seems hard to respond adequately to this fact in the practice of academic research and education. As Schön (1987) points out in the quotation above, universities have no trouble to identify the disciplinary nature of a certain issue. However, problematizing and acting upon them from an interdisciplinary point of view, proves to be much more difficult. How can we organise interdisciplinary education within a discipline-bounded institute? Or more specifically: how can we train students to address interdisciplinary urban problems effectively, if we are unable work around our school's disciplinary walls? In our contribution to this special issue on design education, we introduce the concept of UDM as an interdisciplinary domain of practice, research and education. This domain recently emerged within a Dutch faculty of architecture and the built environment-a school that is hardly free from territorial politics, but has nevertheless found the institutional space and momentum to create activities in research and education to which long-standing and more or less entrenched disciplines like planning, urban design, real estate, building law, business management, and policy sciences are supposed to deliver, as is visualized in Fig. 1.

The demand for professionals who possess the knowledge and skills to organise processes that lead to attractive and just urban environments is growing. And indeed, institutions in the developing world often look at developed countries to deliver these 


\section{Fields of Research and Education}

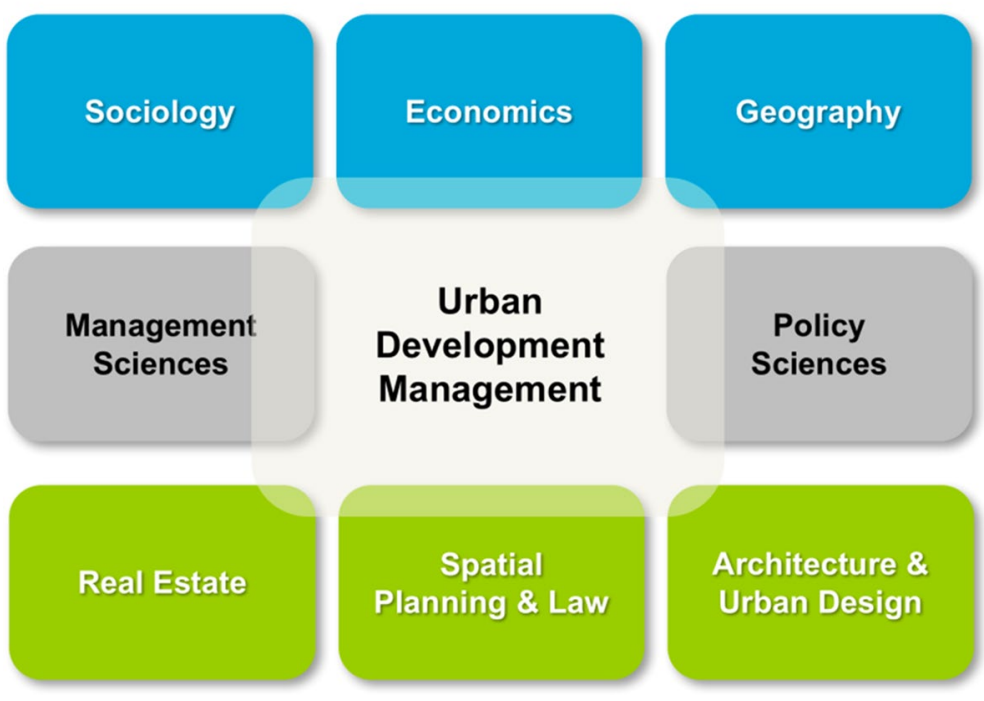

Fig. 1 Urban development management (UDM) as an interdisciplinary field of research and education

professionals, not least through exchange programs and academic pedagogy. In this regard, Mazur (2015) argues that modern engineering education should be a reflection of the professional world, and that creating an interdisciplinary situation happens almost naturally when complex problems are addressed (Klaassen 2018). But while it is clear that interdisciplinary research and education has an important role to play in our global urban era, university teachers are often struggling to understand how to enable students to develop interdisciplinary knowledge and skills, and help them to reflect on the relationship between practice and theory from an integrated angle. The case explored in this paper is an UDM course taught at Delft University of Technology in The Netherlands over the last decade. It provides an example of a role-playing course that incorporates principles of interdisciplinary and experiential learning.

It this paper, we build on recent and timeless insights into interdisciplinary work and practice-theory relations in urban studies. Based on a literature review, in "Pedagogical concepts behind urban development management" section we will discuss various key features regarding interdisciplinary education and the role of experiential learning and role-playing to implement interdisciplinary education in UDM education. "Analytical framework and methodology" section elaborates on an analytical framework and research methods applied for this paper. In "The urban redevelopment game course" section, we will elaborate on our definition and operationalisation of interdisciplinary experiential learning in a course called the Urban Redevelopment Game. "Analysing the urban redevelopment game course" section briefly analyses how interdisciplinary teaching principles are incorporated in the this course, and "Evaluating the course" section evaluates the effectiveness of the course for its interdisciplinary and experiential nature. We will present our main conclusions in "Conclusions and challenges" section. 


\section{Pedagogical concepts behind urban development management}

In this section, we present a conceptualisation of the pedagogy of UDM that consists of two main characteristics: interdisciplinarity and experience. Hence, we will first elaborate on the idea that UDM implies interdisciplinary education. After exploring how interdisciplinarity can be more generally approached and understood, we answer the question how it may be implemented in education with regard to the knowledge and skills students are expected to attain. Secondly, we will describe the idea that a continuous reflection between theory and practice is needed in UDM education. We elaborate how theory-practice reflections can be organised through experiential learning, and what skills students need to reflectively connect practical experience to theoretical concepts.

What is the sense of interdisciplinary education? Three well-known arguments are provided by Stember (1991: 2). The first, intellectual argument holds that ideas in any field are enriched by theories, concepts, and methods from other fields. Next to that, a second, practical argument recognises the idea that the problems of the world are not organised according to academic disciplines. Finally, there is a pedagogical argument for interdisciplinary studies: learning is hindered by fragmentation, and evaluations of educational programs have regularly called for greater coherence and integration of different disciplines. Where multidisciplinary provides different perspectives on a problem or an issue, interdisciplinary integration brings 'interdependent parts of knowledge into more or less harmonious relationships through strategies such as relating part and whole or the particular and the general' (ibid: 4). Ideally, an educational program in the urban field thus consists of multidisciplinary as well as interdisciplinary components.

Positioning interdisciplinary academic programs, such as UDM, is less easy and obvious than it probably seems to be. Most often, universities are organised by departments of separate disciplines. Hence, scholars have been largely educated within their own separate disciplines, and many academic journals are related to a certain discipline-with their own disciplinary assessment criteria - and even students are often expected to major in a specific discipline to fulfil the requirements of graduation. Although it has been acknowledged that we need both specialists and generalists in academia and practice, specialists appear to be more highly valued. Regularly, a generalist is not perceived as a profound person, but as someone who 'knows very little of a lot of things'. However, according to Campbell (2014), it is not the specialists' capabilities that are needed more, or at least not alone, but rather those of the generalist: 'those capable of seeing beyond the silos of particular specialism, and the courage and creativity to make connections and integrate knowledge across fields of expertise and uncertainty. Greater appreciation of the qualities of the generalist matters in and of itself, but also because in practice being an effective specialist is not just about knowing lots about a narrow area, but being able to connect specialist knowledge to wider questions. Such generalist sensibilities are as important to academic as professional life' (ibid: 289).

Using an interdisciplinary approach or creating generalists does not mean that we simply offer as many disciplinary perceptions to problems as possible, in the hope that someone will pick the cherries that he or she likes. To become professional urban development managers, students need to understand that (1) they have to learn from different views of an urban development problem; that (2) every discipline has its value for problem definitions and solutions; and that (3) using a mono-disciplinary perspective will rarely deliver solutions without any negative effects. In becoming a professional generalist, it is not the breadth of the knowledge, but the "capacity to integrate and synthesize knowledge as 
the basis for arriving at reasoned judgments and in turn identifying appropriate courses of action' (Campbell 2014: 289). However, integrating and synthesizing knowledge from separate disciplines is not easy, because separate disciplines process and structure knowledge in different and distinctive ways (Bradbeer 1999). Confrontations between different disciplines can be problematic because of different languages, rationales, or even implicit value systems that are common within a certain discipline. It was noted by Snellen (2002) that different rationales, for example, within economic, social, and political or law disciplines, are incommensurable, which means that it is epistemologically impossible to integrate them completely. Therefore, students do also need reflective skills to understand the challenges, difficulties and limitations of integrated solutions for urban problems.

Most often, interdisciplinary education programs start with a more multidisciplinary basic program that is an accumulation of different disciplines. Over time, students are also challenged to think and work more interdisciplinary (Stember 1991). They will be confronted with more 'wicked problems': problems requiring more than mono-disciplinary analyses and solutions. Whereas conventional education programs prepare students for the less complex or so-called tame problems, more advanced parts of the education program introduce students to wicked problems and complex problem solving (Balassiano 2011). For example, this implies that students have to learn about uncertainty and political nature of the UDM context, beyond the rationality of engineered plans or feasibility models. There is usually not one good solution for a wicked problem, and thus professionals have to work with variation and selection, and with the knowledge that solutions are always tentative and temporary (Van Gunsteren 1976). Effective planning and design strategies cannot be made from the drawing board, but have to emerge during the course of time and be adaptive to changing circumstances in the urban context.

In terms of skills and competencies, more flexible, adaptive approaches in education are needed. It was argued by van Horen et al. (2004) that within planning sciences that complement technical core knowledge areas, strong emphasis on problem structuring, critical and strategic thinking, and the understanding of the political and institutional context appears to be crucial. Therefore, Van Horen et al. (2004) present a valuable competency structure that consists of three types of competencies. There are analytical competencies needed, such as problem structuring, strategic choice, and critical thinking. Furthermore, technical competencies are needed, such as technological, spatial, design, economic and ecological skills. And last but not least, socio-political competencies are needed, such as communication, conflict resolution and negotiation skills. Since the argumentative turn in social and planning sciences (see e.g. Fischer and Forester 1993) those communicative skills are becoming a larger part of educational programs and are highly valued by practitioners in the field as well [as is shown in the survey by Ozawa and Seltzer (1999)].

Practitioners' valuations of certain skills underline the second characteristic of that we want to elaborate in this section: the importance of continuous interaction between theory and practice within education. There is a number of reasons for consciously integrating practice components into UDM pedagogy. Epistemologically, urban development cannot be studied in a vacuum, as natural scientists are able to do in laboratories. Studying UDM thus means that the knowledge object 'talks back'. It means studying real-life situations with live humans who produce their own narratives and who determine the interpretation of what they are doing in the urban environment in their own unique way. Practitioners' oral and written stories are useful sources for empirical data and insights, and furthermore, for creating shared understandings of urban development practices that may or may not adhere to certain theoretical conceptions. In the words of Whittemore (2015: 76): 'practitioners theorize, too'. Practitioners analyse their practices in their own way and draw their 
conclusions about what works and what not. Those insights need to be transferred into education.

Practitioners' experience and their own theories mirror those of academics-they give them a kind of a reality check. These experiences and theories are worthy sources of information and inspiration, not only for scholars and lecturers but also for students. Therefore, real-life cases need to be studied, usually complemented with practitioner lecturers, in addition or as a prologue to more academic and theoretical lectures and readings. Case-driven education helps students with situated learning in which the focus is on 'the context of learning and the social characteristics of that context, leading to activities that are termed authentic' (Johnston 2015: 87). Exploring practitioners' theories emphasizes 'theory as everyday rather than aloof, and as the source of elucidating references in a variety of challenging situations' (Whittemore 2015: 82). Good lecturers are capable of helping students to mirror and integrate practitioners' experience with more abstract academic knowledge.

Interdisciplinary and practice-oriented education ask for experiential learning. Experiential learning, is a structured activity that focuses on participation and interaction. Additionally, experiential learning involves the learner to create meaning from first-hand experience (Johnston 2015: 87). It implies a very active learning style experience how material and principles are encountered are integrated and applied to new situations (Feinstein et al. 2002). The classic work of the learning cycle, developed by Kolb (1984), helps to further define this active learning process. The learning cycle starts with the first stage of active listening, reading and discovery. In the second stage, the learner has to reflect on and evaluate that experience. In the third stage, creative skills are needed to conceptualize and to create theoretical insights. In the fourth stage, there is room for problem-solving skills and for applying ideas that are gained from experience. It has to be underlined that this learning cycle needs attention in guiding students during their participation in UDM courses. Especially students with design backgrounds, but also practitioners with very practical 'getting things done' work styles, run the risk of using their problem-solving skills too soon without thoroughly going through the earlier stages of learning.

\section{Analytical framework and methodology}

In the previous section, we introduced the most important pedagogical foundations of UDM education. Interdisciplinary learning consists of two conditions: an accumulation of separate disciplinary perspectives (multi-disciplinarity), and a confrontation between the insights that are derived through the different disciplinary approaches, resulting in integration and reflection. Those two elements of interdisciplinarity (accumulation and confrontation) are very important, because without sufficient available specialist knowledge, a generalist cannot do his or her work of creating integrated solutions for urban development problems. At the same time, reflection on the coherence of separate disciplines is needed to avoid the appearance that education offers only multidisciplinary knowledge without developing interdisciplinary insights and reflections.

Next to interdisciplinary learning, we have also described the idea of theory-practice integration through experiential learning. Firstly, this implies continuous interaction between theory and practice in UDM education in order to develop analytical, technical and socio-political skills. Secondly, it involves doing an active 'reality check' on the theories conveyed to students by involving reflective practitioners in UDM education. Finally, and foremost, we pointed out that an UDM course needs to attend to the stages in Kolb's 
(1984) experiential learning cycle, teaching students to consciously discover, reflect upon, conceptualize, and test solutions to a perceived urban problem.

\section{Framework}

The above two components of UDM education come together in a framework and methodology for analysing courses that seek to combine both interdisciplinary and experiential learning. Each row depicted in Table 1 represents the elements discussed above in our two main categories. The columns are divided into the elements of constructive alignment in higher education teaching (Biggs 1996): learning objectives; teaching and learning activities; and feedback and assessment methods. The framework thus allows to systematically analyse the different parts of a course with regard to their capacity to stimulate students to reach interdisciplinary and experiential learning objectives. Identified through the vocabulary of Bloom's taxonomy, we will be able to answer the general question addressed in this paper: whether students recognize, evaluate and can apply different disciplines to work in an interdisciplinary context with the help of the interdisciplinary education?

\section{Case: the urban redevelopment game course}

The case selected for analysis is an UDM course that is part of the core curriculum of the Department of Management in the Built Environment at the Faculty of Architecture and the Built Environment in Delft, The Netherlands. The full name of the course is The Urban Redevelopment Game: Integrating Urban Planning, Design, and Property Development. It is an educational effort to combine the interdisciplinary and experiential learning sought for, and because of the authors' involvement in designing and developing the course, it is a well-suited pilot case study. We deem it a case study because we observed and analysed the components of the course within its real-life university setting. We make use of role-playing to achieve experiential learning. According to Feinstein et al. (2002: 734), role playing allows participants to "immerse themselves in a learning environment by acting out the role of a character or part in a particular situation". Obviously, the execution of an UDM

Table 1 Framework for analysing courses that combine interdisciplinary and experiential learning

\begin{tabular}{llll}
\hline $\begin{array}{l}\text { Learning } \\
\text { objectives }\end{array}$ & $\begin{array}{l}\text { Teaching and } \\
\text { learning activi- } \\
\text { ties }\end{array}$ & $\begin{array}{l}\text { Feedback and } \\
\text { assessment } \\
\text { methods }\end{array}$ \\
\hline
\end{tabular}

Interdisciplinary learning

Accumulation

Confrontation

Problem assessment

Process evaluation

Experiential learning

Discovering

Reflecting

Conceptualising

Testing 
course cannot be mimicked, simulated, or reduced to an experiment-it has to be studied as it is implemented with real students, teachers, assignments, presentations and tests.

As involved teachers, we are cautious to prevent bias or misinterpretation of our observations and experiences. To triangulate and scrutinize our assessments, we thoroughly discussed our data-i.e. curriculum documents and assignments, lecture material, study material and tests-with colleagues and students alike, probing different ways of positioning them within our pedagogical frame. Both quantitative and qualitative products or evaluations of the course (student presentations, reports, feedback, and survey results) were used to explore to what extent students have become aware of their interdisciplinary learning experiences and the theory-practice integration aimed for in the course. In the following sections, we present our case study and consecutively discuss our results by identifying both its potential and limitations in delivering the learning outcomes aimed for. We conclude this paper with answering our main research question and pointing out some specific lessons regarding designing and teaching course focused on interdisciplinary experiential learning.

\section{The urban redevelopment game course}

The urban redevelopment game course is provided to master students in the final quarter of the first year of the Management in the Built Environment (MBE) track, which is a 2-year Master of Science (M.Sc.) programme. It is available to students from architecture, urbanism, building technology and in some cases from other relevant studies outside the faculty as well. A number of students who study construction management and real estate from other Dutch universities, and students from other European universities enrol in this course. The inflow of students from different disciplines increases the diversity of the student group. Before this course starts, most students have already been introduced to management, real estate, economic and financial aspects of real estate development. This allows the course to assume that students will be able to take on the role of specific actors in what can best be described as a real-life simulation of a strategic and collaborative development plan-making effort. To some extent, students that enrol thus already have some skill in designing urban plans, and performing financial-economic feasibility and real estate market analyses. The course asks students to adopt the role of actors who have a predefined stake and position in the urban development process of a particular urban area. A key product of the course is a joint urban development plan-a plan that proposes a (re) development program for the area under study, but also takes into account the process of land assembly and preparation, the financial feasibility of different development scenarios, the phasing of the urban development, and the potential collaboration models actors could employ to exchange risks and resources. Hereinafter, we use the constructive alignment elements as identified by Biggs (1996) to describe the characteristics of the course. This is in line with an argument made by Klaassen (2018) that the design of interdisciplinary education needs to consider constructive alignment, amongst others.

\section{Learning objectives}

The learning objectives of the course that contribute to interdisciplinary thinking are threefold: (1) students understand the changing context of global and local environment and economic, social and cultural elements which contribute to various urban problems; (2) 
students are able to analyse the social-economical and urban context of a real-time, ongoing project and as well as the potential status and function the location can possibly achieve in the future; (3) student are able to work in multidisciplinary teams, negotiate and communicate with different parties, in order to develop a common urban strategy for the chosen urban project that takes into account spatial possibilities, financial feasibility and according implementation strategies.

Using the analysis framework, we can see that the first learning goal in the course focuses on the objective of understanding and the second and third learning goals are more tuned to higher level learning - analysing, applying, evaluating and creating. That means that during the course, teaching and learning activities aim to address how students acquire skills beyond technical skills, and more focused on analytical skills, experimental learning, confrontation, solution, reflection and accumulation. Furthermore, the concrete outcomes of the course (developing an urban strategy before a deadline) is an important focus for an interdisciplinary course. Such concrete outcome serves as a strong foundation for the team to 'deal more strategically and rationally with conflicts concerning curriculum content' (De Greef et al. 2017).

The design, preparation and implementation of the course makes full use of knowledge from the practice. To prepare for the real project and the possible designation of specific roles, we involve project bureaus that are in charge of the project in the brainstorming process. For example, when we prepared the Zestienhoven Project nearby Rotterdam-theHague Airport, both Rotterdam Development Corporation OBR and Schiphol Real Estate BV were involved from the initiative phase to help define the problems and involved stakeholders, provided up-to-date information, guided the fieldwork and participated in students' final presentation. For more practical experience, guest lectures are involved to provide knowledge and lessons learned from on-going projects. Students are encouraged to interact with experts on specific disciplines in reality to understand their task, challenges and constraints.

\section{Teaching and learning activities}

The course is strongly tuned to the application and integration of knowledge from various disciplines visualized in Fig. 1, and operates on an urban scale. Consequently, rolesimulation for a real-life urban project is primarily used for teaching and learning activities. In this course, students are required to work in multidisciplinary teams of around 10-14 group members. Students are asked to collectively draw up an urban development (UD) plan by means of role-play. In this UD plan students are asked to demonstrate their understanding of the potential and constraints of the location, the economic, spatial, legal and financial considerations of the location, and possible stakeholder interaction necessary for carrying out the plan. To simulate reality, the students are grouped into different actor roles based on organisations that also appear in UD reality: municipality departments, real estate developers, housing associations, etc. For individual group members to work in an interdisciplinary team it is important to have motivated and committed students playing a specific role. Therefore, we assign students to a role based on their motivated preference determined before the course commences. In addition, we mix students to create a balance in gender, cultural background and existing competence and knowledge level.

The students start the course with a number of theory and guest lectures from university staff with different disciplinary background and from practitioners. These lectures address 
the academic in-depth understanding the urban challenges, address not only the various knowledge from different disciplines, but also illustrate how topics from different disciplines are related and could be integrated. For instance, students learn about the importance of the urban context, and how actors behave and interact in a number of urban development projects, followed by discussions about various urban development strategies in different economic circumstances and institutional settings. Given the need for obtaining theoretical knowledge from different fields of expertise, lectures become the most appropriate choice for efficient knowledge transfer. With this knowledge, students learn to understand, appreciate, reflect on and criticise other perspectives and disciplines and urban development as an interdisciplinary practice.

To prepare the students for their own mono-disciplinary role, role lectures are given to provide an overview of the emphasis and interest of a particular role. Role supervisors (lecturers in specific disciplines) are assigned to discuss the progress with students in weekly role group meetings, in which they also provide feedback to adjust students' learning process. To integrate the knowledge from different perspectives, group supervisors (lecturers with broad knowledge on urban development) are assigned to an individual group consisting of different roles. Group supervisors also give advice to the process manager's role in the group in order for them to effectively coordinate the group interaction towards productive results. Both the role and group supervision, as well as the lecturers, represent a number of disciplines within the faculty and beyond. A strong support from the leadership at faculty department level allows the interdisciplinary education to receive infrastructure support. This is an essential condition to create the success of such interdisciplinary education as suggested by Stember (1991).

The students start with the preparation phase of understanding their own roles, and how their roles are involved in the study location, thereby receiving regular role supervision. This didactical choice is in line with argument made by Stember (1991: 8) that 'one of the most important investments of time and effort in commencing interdisciplinary enterprise is the preliminary exploration by all members of what the discipline can offer to the problem of interest'. In the urban redevelopment game course, every week students are asked to deliver their working results by presenting it to one another. This can be a plenary session to the whole class, to their individual group, and to the panel and wider audience, depending on the goal of the presentation. Using such opportunities, each specialist can inform and educate other team members by presenting both theoretical and empirical views, under supervision of group supervisors. This openness helps to achieve a constructive and comprehensive atmosphere, allowing different methods and perspectives to be tolerated and even incorporated as 'indicators of pluralism and diversity, hallmarks of interdisciplinary efforts' (Stember 1991).

After students develop substantive specialised knowledge, they enter into the negotiation phase, in which all divergent visions and interests of specific roles are discussed between students to achieve certain agreements on overall plan design, functional program, land price, financial feasibility, contract forming etc. By applying their specialized knowledge on a real-life project, a number of competences following Bloom's taxonomy, like comprehensive, application, analysis and synthesis, are trained during this phase. Students explore individually and collectively what one specialized discipline offers to the problem of interest. The negotiation result can be seen as an outcome of individual students applying, integrating and synthesizing their specialized knowledge. Besides group supervision and role supervision, a workshop called an urban development charrette is organized to help students to translate abstract concepts and requirements of different disciplines into visual products. There are some general procedural rules to define the progress of 
negotiation and integration, but the path towards the outcome is not clear-cut. Rather, the result is often dependent on individual's competences, characteristics and leadership. By sharing, debating, arguing and convincing each other's perspectives, methods, and disciplines, synergies are reached.

The negotiation phase is followed by the exploration phase to let students translate all negotiation results into visual documents, including vision, development phasing, land transfer and sustainability strategies, and to present them at the final group presentation plenary meeting to a jury and the public. A broad jury panel is invited to join the final presentation session. This jury panel typically includes project managers, planners, land economists, real estate developers and/or managers from housing associations involved in the area. The commitment of these practitioners in the whole education process is an important prerequisite for the overall quality of the learning outcomes and experience. A prize is awarded for the group that appeals most to the criteria defined by the practitioners' jury. The competition gives students a strong motivation to improve the group performance, but does not have decisive weight in evaluating students' performance in the course. Group evaluation sessions are planned immediately afterwards, with students reflecting on their learning curve in the whole course chaired group supervisors. Students also evaluate the performance of their peers via two peer reviews, providing other team members with tips for improving their performance in and contribution to the group. The peer review is a good reference for group supervisors to evaluate the performance of individual team members, and is taken into account in student role assessment.

In our case, there are different ways to integrate theory with practice by means of experiential learning: with practice information (through documents, illustrations, case studies, interviews, etc.); with practice lectures (through guest lectures from practitioners); with practice experience (through consultancy to provide advice to individual students who play certain roles) and with practice advisory (through evaluation forms and jury feedback from practitioners).

\section{Feedback and assessment methods}

To address the interdisciplinary results, students are asked to work on specified assignments and deliver several products for assessment. One assessment is to ask students to write an essay analysing the project used in role simulation. Students are evaluated on the qualitative argumentation of analysing the various opportunities and constraints of the urban development process of the study location in the practicum, through the application and integration of different theories in relation to design and management solutions.

A second assessment tool is to evaluate students' final design solution, examining how different interests and requirements of stakeholders are incorporated in the final UD plan. Group supervisors compare the end products and see how well the team addresses the problems and how well they integrate and problematize solutions from different disciplines to make the final product. The arguments for strategies in planning and design solutions, functional programme choices, land transfer, development phasing, financial schemes and sustainable measures are all combined into the final plan. These aspects of the UD plan are all described, elaborated on and argued for in a joint (identical) chapter, part of the individual role final report by students.

The third assessment tool is to evaluate the students' individual final report. The role report should define the arguments behind the plan, corresponding urban development 
strategies that follow, and reflect the learning process in developing such a joint plan as an individual and as part of a team. For individual students, this report is assessed by both the role and by group supervisor with equal weight. The quality of the report is judged by how far the students analyse the urban challenges by exploring existing academic debate, how well the students argue about their solution based on integrating different knowledge lines, and how well students reflect their experience in role simulation by combining on-going academic debate, role-simulation and project in reality.

\section{Analysing the urban redevelopment game course}

The description of the urban redevelopment game course above provides ground for substantiating how it incorporates interdisciplinary teaching principles. Table 2 indicates main learning objectives, teaching and learning activities, and feedback and assessment methods for both interdisciplinary and experiential learning aspects. Some indicated course elements have not been described within the previous section, but have been added to the table for reasons of completeness. The table illustrates that each aspect of both types of learning incorporates multiple diverging and sometimes overlapping course elements. On the one hand, for course coordinators this implies that effectively designing and organising an experiential and interdisciplinary course like the urban redevelopment game course requires an explicit and well-thought-out constructive alignment of learning objectives, activities and assessment. On the other hand, for students it might be difficult to understand the true value of their interdisciplinary and experiential learning, as aspects of these two types of learning are integrated throughout various elements of this course.

\section{Evaluating the course}

In previous sections, we identified how interdisciplinary and experiential learning are addressed in the learning objectives, teaching and learning activities, as well as feedback and assessment methods of the urban redevelopment game course. Now, we raise the question whether students recognize, evaluate and have actually learned to apply and synthesize different disciplinary perspectives in an experiential manner during the course. This enables us to critically examine the interdisciplinary and experiential character of course. With this question in mind, we have conducted a number of evaluations of the course between 2008 and 2017:

(1) Quality Assurance Reports (QAR) are considered as the most reliable source of evaluation. They are conducted by an independent Quality Assurance Team of the faculty, using on-line questionnaires. The evaluation focuses on the overall quality, learning experience, work load, and relation in content between courses. All students who have followed the course can participate anonymously online and usually around half of the students (20-30 students in total) submit their answers;

(2) Panel Discussion Meetings (PDM) with students are organised yearly after the course by the student association from the department, with a main focus on improvements of learning experience for students. Around one-fifth of the students are invited to have such a face-to-face discussion; 


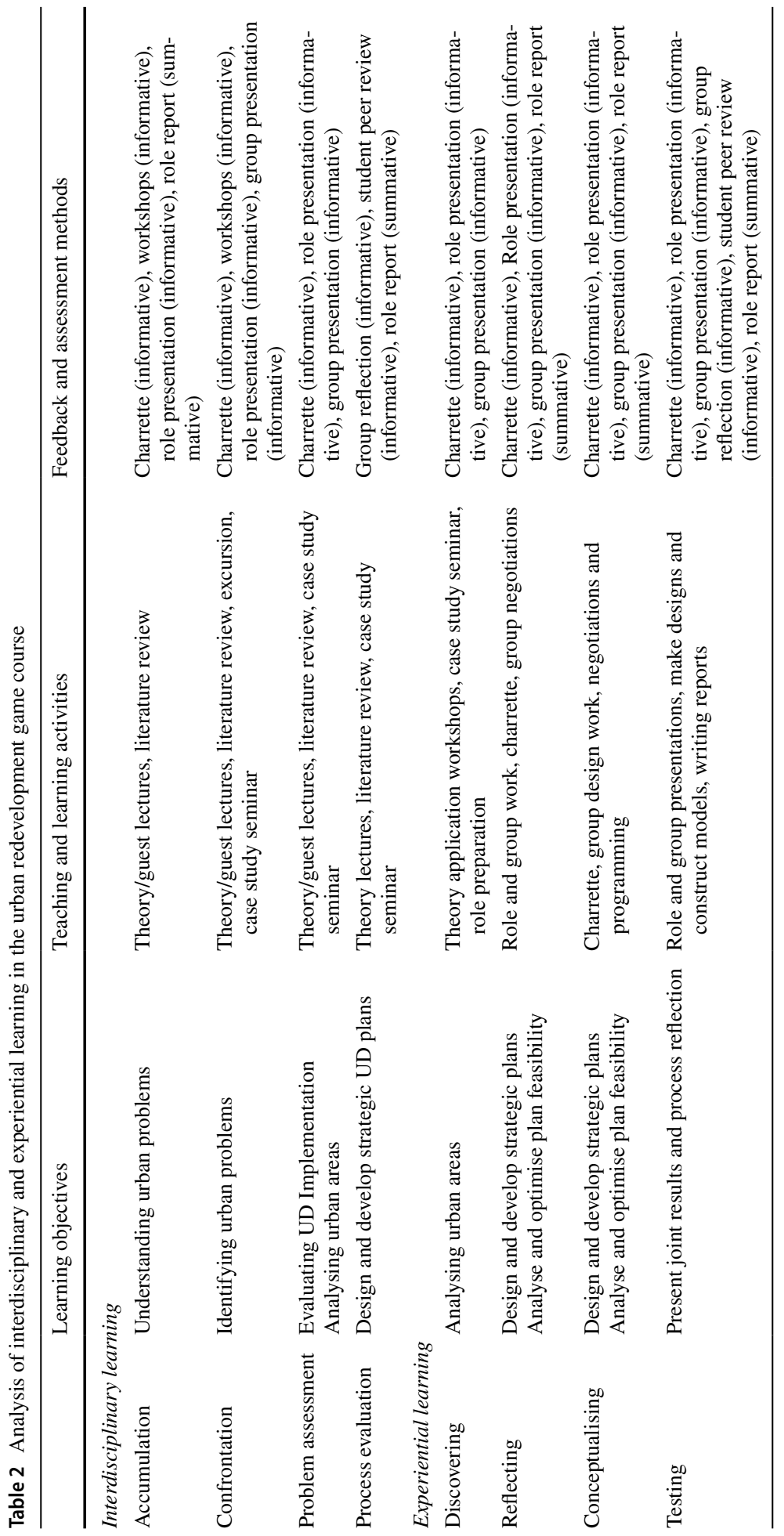


(3) A Teaching Staff Evaluation (TSE) organised by the coordinator and teaching staff, with focus on course content and learning effectiveness issues. Often the invitation is based on special concerns arising during the course and availability of students.

From the five reports and various meetings conducted between 2011 and 2017, we found out that students in general comprehend the value of interdisciplinary education and the connection of the course with real life experience and team work. One student summarized his/her impression: 'Intense, with a lot of content and a nice combination between theory and practice and team collaboration' (QAR 2010-2011). Students strongly agree with the statement that they have developed skills in negotiation, decision-making and conflict management through role-simulation, with an average grade of 3.8 out of 5 (QAR 2016-2017). Students are mostly impressed by the close connection between education and practice. For example, most student state that 'the connection between theory and practice provide comprehensive understanding of the urban challenges faced in the study location'. 'The course gives good insight in the different work fields and parties involved in urban redevelopment projects" (PDM 2015-2016). 'The negotiations during the game are a good practice for the real life' (PDM 2015-2016). Students are especially positive with the statement that 'Interaction with practitioners (through lectures, consultancy and excursion) provides useful insight complementary to the academic knowledge I have learnt in class', with an average grade of 3.4 out of 5 (QAR 2016-2017).

Students learn to work in a team with different disciplines and attempt to understand, appreciate and agree with another's perspective, cultivate the diversity and respect for each other in their pluralistic view. 'The multi actor basis is the most challenging part of the course' (PDM 2015-2016). One student stated: 'During the process of working together in groups, we learned a lot from each other [roles]'. 'The connection with the reality of today's built environment and the integral solution connects all the aspects of management in the built environment—-developing, designing, managing, etc.' (QAR 2012-2013); (the course) gives a good impression of the process between parties and the aspects to be considered (QAR 2010-2011). One student noticed that the course provides 'a chance to understand various actors and influence on each other' (QAR 2010-2011). Another student said: 'I found it very much instructive and fun to negotiate and become aware that other parties have other interests' (QAR 2011-2012). In the QAR (2016-2017), many students used words like 'synergy', 'collaborative', 'commitment', 'respect' to describe their learning experience in their teamwork. Students appreciate collaborative working and enjoy the group dynamics: 'The idea behind it [the course] is very good, and working in groups makes is a fun way to work. I think this can come in handy in practice, which from my point of view is the most important goal the course has reached.' (QAR 2010-2011). Another student comments: 'Working together in a group of 10 persons is a challenging but very educative and positive experience!'.

Despite positive reflection to the course there are also a number of issues raised by students to alert us regarding the urban redevelopment game course as an interdisciplinary education. For example, students use words like 'challenging', 'tension', 'pressure', 'lack of participation' to reflect the difficulties in a teamwork environment. Also, although the interdisciplinary concept is the core of the education, it is difficult to neglect some students have no intention to embrace the other perspective beyond the subjects he/she likes and tend to focus on reaching their own role objectives rather than group results. In addition, students are concerned with the unevenly distributed workload and different assessment standards used by role supervisors. 'There was also diversity in the study load per role. 
Some roles are more intense than the others' (QAR 2014-2015). One student expressed his/her great frustration regarding these issues: 'Grading varied greatly between different roles. People playing other roles with far greater contributions to their teams received lower grades' (QAR 2011-2012).

In conclusion, these evaluations implicate the following. First, students are well aware of the fact that the course represents an interdisciplinary effort of team members to integrate varying disciplinary content and aspects into an urban development plan. Second, students value the experiential nature of the game as it resembles urban development practice in a somewhat simplified manner. Student concerns mainly illustrate the complexity of interdisciplinary experiential group work, with the dissatisfaction about the inability of individuals to perform to group expectations. Third, in the TSE evaluations the issue of the difficulty to align objective judgements by many teachers on the performance of individual students remains an issue. In addition, a reoccurring TSE issue is the quality of student reflections in their final reports, which in general show limited abilities to academically reflect on the student's own learning process and insights gained regarding both interdisciplinary and experiential learning. Therefore, in these fields there might be room for improving the course activities and assessment methods.

\section{Conclusions and challenges}

Contemporary urban challenges call for new professionals that are able to engage in the translation, synthesis and integration of knowledge from different fields. The urban redevelopment game course is an attempt to incorporate interdisciplinary teaching principles in the field of UDM education and experiential learning through role-playing. In this paper, we set out to explore and evaluate to what extent we achieved this goal, and questioned whether students can recognize, evaluate and apply insights from different disciplines by working together in this setting. After describing and examining the learning objectives, teaching and learning activities, feedback and assessment methods, and discussing student evaluations, we can answer these two questions with more certainty.

The first question is answered by perceiving the course in total as an interdisciplinary learning activity. Although the course starts with multidisciplinary knowledge and the knowledge students acquire is obtained from different disciplines, it does not remain at the level of providing 'the silos of separate specialisms'. Rather, through role-playing, knowledge from different disciplines is applied to analyse the context, content, actors and means of implementation of a real-life urban project. The development of the course follows Bloom's taxonomy cognitive domains, with a focus on higher level of learning skills such as application, analysis, synthesis and evaluation, accumulation, confrontation, reflection on problems and solutions-as identified in our analytical framework. It also makes use of the strategies of interdisciplinary work, such as selecting appropriate members and leaders, establishing ground rules, explicating and resolving differences and infrastructure support. This is aimed at ensuring that the course creates an open and tolerant environment for an exchange of views and perspectives among team members, as well as commitment to finding common interest and looking for the potential contribution of each particular discipline.

Especially the teaching and learning activities in the negotiation phase serve as a platform for integrating and applying knowledge from different disciplines. Within their own 
groups, students representing their own disciplines argue that they simultaneously defend their own interest and make compromises, which resolves in an in-depth understanding and incorporation of insights from separated specialisms. The group supervisor and the process manager play their own parts in facilitating the knowledge integration process. The result of this process - the urban development plan, and students' arguments on the integration path towards the end result in a final report shows the growing capacity of students in recognizing, evaluating and applying different disciplines to work in an interdisciplinary context with the help of the interdisciplinary course. Student evaluations confirm the interdisciplinary learning experience of the course. With these learning experience, students are able to create a sense of generalist sensibilities and learn to connect specialist knowledge to wider questions, as is suggested by Campbell (2014).

Second, the question is answered from the perspective of urban redevelopment game as a form of experiential learning. The course is clearly case-driven, aimed at confronting students with a wicked problem, resembling a high level of breadth and complexity in the problem (Klaassen 2018). In the lectures, lecturers attempt to trigger academic discussions among students about the different dimensions of the urban problem, and surpass monodisciplinary thinking. In the role-playing, the assignment also demands students to consider the dynamics of urban development processes. This experiential learning gives students great incentives to attain analytical, technical, and socio-political skills critical for effective practitioners, and creates an opportunity for students to benefit from theory-practice reflection. Student evaluations also confirm that role-playing and group work assists in creating experiences that resemble urban development practice situations. However, the ability of students to critically reflect on the relationship between theory and practice and their obtained insights regarding experiential learning in final student reports is often limited.

Overall, we conclude that the urban redevelopment game course does a fair job in facilitating interdisciplinary learning - covering accumulation, confrontation, problem assessment and process evaluation aspects-but that explicit attention needs to be paid to the extent to which mono-disciplinary knowledge has actually been integrated into interdisciplinary results. There is a chance for teaching staffs to stress the importance of this issue to students by making it an explicit assessment criterion for their report in order to enable students to reflect on this matter more consciously. With regard to experiential learning, we conclude that its aspects-discovering, reflecting, conceptualising and testing - are all covered within the course. Within a short timeframe and scholarly setting, students can to a certain degree experience what is like to design an urban plan through interdisciplinary work. Nevertheless, more explicit attention should be paid to addressing and identifying the limitations of experiential learning relative to actual practical experience.

In our view, the added value of our findings is twofold. First, in this paper a deliberate effort is made to link didactical aspects and insights from interdisciplinary and experiential learning to each other. We stressed the importance of integrating experiential learning activities and objectives into an interdisciplinary learning environment. This has led us to consider the interdisciplinary nature of urban problems together with the students in classroom settings, and provide them with a learning-by-doing assignment that helps them to integrate insights and become fit for reflective practice. But our evaluation also demonstrates the importance of paying attention to the accumulation and confrontation of knowledge from different disciplines. The tensions that often emerges between specialists in practice are often neglected in multi-disciplinary educational programs, especially when courses are too theory-oriented or of mono-disciplinary content. Therefore, experiential learning through role-playing combined with guest lecturers from multiple fields is science 
and practice can help students recognise interdisciplinary problems and the deal with inevitable tensions between disciplinary perspectives and solutions.

Second, the introduced framework in this paper enables other instructors and lecturers to more consciously design and critically assess interdisciplinary and experiential learning courses. No doubt, the framework needs further applications and testing in other courses to prove its usefulness and gain its full potential. Integrating the different disciplinary criteria for research and education is not an easy task. It could raise questions such as: 'Is one discipline more important than the other?', or 'How to balance different disciplinary criteria?' In the assessment of academic work, such as essays, theses and other reports, we have to be aware that in some cases, a relatively poor piece of work in mono-disciplinary terms can show great quality from an interdisciplinary perspective.

The described and analysed course in this paper can function as an example for other interdisciplinary experiential courses, especially those concerned with complex urban design, planning and management challenges. Therefore, developing and improving our education demands us to do what we have to ask our students too: understanding and solving urban problems requires spanning across the boundaries between disciplines, between organisational silos, and-indeed—between theory and practice.

Open Access This article is distributed under the terms of the Creative Commons Attribution 4.0 International License (http://creativecommons.org/licenses/by/4.0/), which permits unrestricted use, distribution, and reproduction in any medium, provided you give appropriate credit to the original author(s) and the source, provide a link to the Creative Commons license, and indicate if changes were made.

\section{References}

Balassiano, K. (2011). Tacking "wicked problems" in planning studio courses. Journal of Planning Education and Research, 31(4), 449-460.

Biggs, J. (1996). Enhancing teaching through constructive alignment. Higher Education, 32, 347-364.

Bradbeer, J. (1999). Barriers to interdisciplinarity: Disciplinary discourses and student learning. Journal of Geography in Higher Education, 23(3), 381-396.

Campbell, H. (2014). Specialists and generalists: Are there too many hedgehogs and not enough foxes? Planning Theory \& Practice, 15(3), 287-290.

de Greef, L., Post, G., Vink, C., \& Wenting, L. (2017). Designing interdisciplinary education. A practical handbook for university teachers (Vol. 3)., Perspectives on interdisciplinarity series Amsterdam: Amsterdam University Press.

Feinstein, A. H., Mann, S., \& Corsun, D. L. (2002). Charting the experiential territory: Clarifying definitions and uses of computer simulation, games and role play. Journal of Management and Development, 21(10), 732-744.

Fischer, F., \& Forester, J. (Eds.). (1993). The argumentative turn in policy analysis and planning. London: Duke University Press.

Johnston, A. S. (2015). City section: A pedagogy for interdisciplinary research and collaboration in planning and environmental design. Journal of Planning Education and Research, 15(1), 86-92.

Klaassen, R. G. (2018). Interdisciplinary education: A case study. European Journal of Engineering Education, 1, 1. https://doi.org/10.1080/03043797.2018.1442417.

Kolb, D. A. (1984). Experiential learning: Experience as the source of learning and development. Englewood Cliffs: Prentice-Hall Inc.

Mazur, E. (2015). Key-note address UTwente 25th of October 2015. Tour de Mazur in the Netherlands.

Ozawa, C. P., \& Seltzer, E. P. (1999). Taking our bearings: Mapping a relationship between planning practice, theory, and education. Journal of Planning Education and Research, 18, 257-266.

Schön, D. (1987). Educating the reflective practitioner. San Francisco: Jossey-Bass.

Snellen, I. (2002). Conciliation of rationalities: The essence of public administration. Administrative Theory \& Praxis, 24(2), 323-346. 
Stember, M. (1991). Advancing the social sciences through the interdisciplinary enterprise. The Social Science Journal, 28(1), 1-14.

van Horen, B., Leaf, M., \& Pinnawala, S. (2004). Localizing a global discipline-Designing new planning programs in Sri Lanka. Journal of Planning Education and Research, 23(3), 255-268.

Van Gunsteren, H. (1976). The quest for control. London: Wiley.

Whittemore, A. H. (2015). Practitoners theorize, too: Reaffirming planning theory in a survey of practitioners' theories. Journal of Planning Education and Research, 35(1), 76-85.

\section{Documents}

Panel discussion meeting result, developed by the BOSS student association, 2015-2016, Faculty of Architecture and the Built Environment, Delft University of Technology.

Summary of survey results, Quality assurance report 2010-2011, defined by Quality Assurance BK, Faculty of Architecture and the Built Environment, Delft University of Technology.

Summary of survey results, Quality assurance report 2011-2012, defined by Quality Assurance BK, Faculty of Architecture and the Built Environment, Delft University of Technology.

Summary of survey results, Quality assurance report 2012-2013, defined by Quality Assurance BK, Faculty of Architecture and the Built Environment, Delft University of Technology.

Summary of survey results, Quality assurance report 2014-2015, defined by Quality Assurance BK, Faculty of Architecture and the Built Environment, Delft University of Technology.

Summary of survey results, Quality assurance report 2016-2017, defined by Quality Assurance BK, Faculty of Architecture and the Built Environment, Delft University of Technology.

Publisher's Note Springer Nature remains neutral with regard to jurisdictional claims in published maps and institutional affiliations. 